\title{
Recent Advances in Rare Earth Complexes Bearing Allyl Ligands and Their Reactivity towards Conjugated Dienes and Styrene Polymerization
}

\author{
Jashvini Jothieswaran, Sami Fadlallah, Fanny Bonnet * and Marc Visseaux * \\ UMR 8181-UCCS—Unité de Catalyse et de Chimie du Solide, ENSCL, Centrale Lille, University Artois, \\ University Lille, CNRS, F-59000 Lille, France; s1438669@sms.ed.ac.uk (J.J.); \\ sami.fadlallah@etudiant.univ-lille1.fr (S.F.) \\ * Correspondence: fanny.bonnet@ensc-lille.fr (F.B.); marc.visseaux@ensc-lille.fr (M.V.); \\ Tel.: +33-320-434-091 (F.B.); +33-320-336-483 (M.V.)
}

Received: 15 November 2017; Accepted: 30 November 2017; Published: 5 December 2017

\begin{abstract}
This mini-review focuses on recent advances on the synthesis, structure, and characterization of allyl-based rare earth organometallic complexes, with emphasis on their ability to catalyze the polymerization of non-polar monomers such as conjugated dienes, styrene, and their related copolymerization.
\end{abstract}

Keywords: rare earths; allyl; conjugated dienes; stereoselective; polymerization catalysis

\section{Introduction}

Organometallic rare earths (REs) chemistry was first introduced at the beginning of the 20th century [1] but for some time it attracted little interest due to the lack of characterization-and, thus, understanding — of these highly-reactive compounds. However, since the 1970s, with the advent of modern techniques of analysis and synthesis, it became possible to better apprehend the structure and reactivity of organometallic RE complexes, which promoted the growth of research in this field of chemistry and its application to catalysis. Thenceforth, chemists realized that the thorough study of the reactivity of allyl derivatives of the rare earths, besides alkyl and hydride derivatives, could greatly benefit the comprehension of mechanisms involved in rare earth-catalyzed polymerization of olefins and conjugated dienes [2-6].

Rare earth-based allyl complexes are a relatively new area of organometallic chemistry of the RE elements and it was not until 1975 that the first series of rare earth complexes bearing an allyl ligand, $\mathrm{Cp}_{2} \mathrm{RE}\left(\mathrm{C}_{3} \mathrm{H}_{5}\right)\left(\mathrm{RE}=\mathrm{Sm}\right.$, Er, Ho and $\left.\mathrm{Cp}=\mathrm{C}_{5} \mathrm{H}_{5}\right)$, was successfully synthesized by Tsutsui and Ely [7]. Thereafter, allylic-substituted rare earths, ranging from mono- to tetra-substituted allyl complexes, have been explored, and the group of Taube was probably the most successful in this area during the 1980s and 1990s [8]. In terms of reactivity, the allyl moiety is of specific interest because it makes it possible to carry out a certain number of elementary organometallic reactions, such as those involved in catalytic processes (insertion reactions [9], hydrogenolysis [10,11], hydrosilylation [12], alkyl exchange [13], etc.). Consequentially, the [RE-(allyl)] species has demonstrated its ability to catalyze polymerization reactions, with a particular behavior towards non-polar monomers (Scheme 1), some of which are highly stereo-selective [14-16]. The [RE-(allyl)] moiety has also been studied as a model for the chain initiation in olefin polymerization [17], and the coordination of the allyl ligand within the complexes, as well as the specificity of the rare earth metals used have shown to vary the outcome of the polymerizations. 


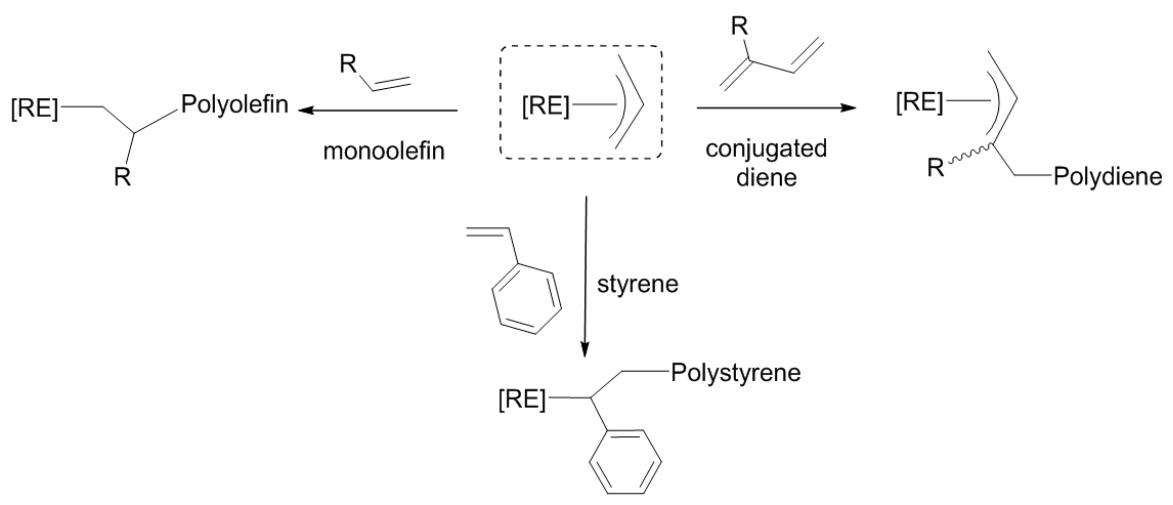

Scheme 1. Non-polar monomers polymerized by RE(allyl) compounds.

In 2010, Carpentier et al. [18] reviewed allyl rare earth complexes that had been studied over the past decades, along with their reactivity. Since then, a number of reports have been published that enlarge the knowledge on this particular class of compounds. In this review, we focus on the very recent development dealing with RE allyl compounds, highlighting their ability to catalyze the polymerization of non-polar monomers, such as butadiene, isoprene, styrene, and related co-polymerizations.

\section{Allyl Complexes for the Polymerization of Butadiene}

Polybutadiene (PB), arising from the polymerization of butadiene, a petro-sourced monomer, was first synthesized in the 20th century by using a sodium-based catalyst. The most notable advancement regarding the polymerization of dienes was the discovery of the Ziegler-Natta catalysts, which are still being used for industrial scale process for more than half a century, producing highly stereoregular cis- or trans-PB (Scheme 2) [19]. Rare earth complexes, and among them allyl-based catalysts, took their part in this context showing their ability to produce highly stereoregular PB with high activities, especially with the studies done by Taube's group $[8,14,20]$.

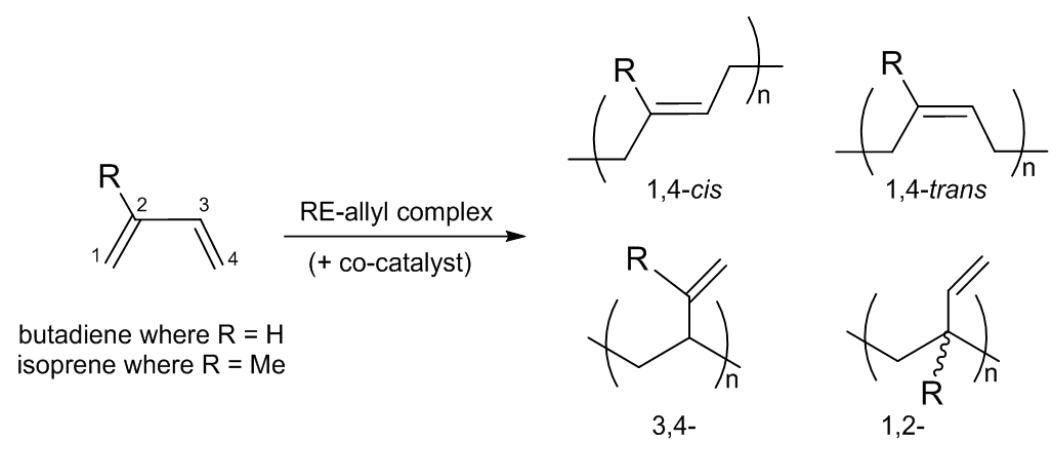

Scheme 2. Polymerization of butadiene and isoprene by means of RE(allyl)-based catalysts.

At the end of the 2000s, Okuda and co-workers reported the synthesis of a series of mono-cationic bis-allyl complexes $\left[\mathrm{RE}\left(\eta^{3}-\mathrm{C}_{3} \mathrm{H}_{5}\right)_{2}(\mathrm{THF})_{3}\right]^{+}\left[\mathrm{B}\left(\mathrm{C}_{6} \mathrm{~F}_{5}\right)_{4}\right]^{-}\left(\mathbf{1}_{\mathrm{RE}}, \mathrm{RE}=\mathrm{Y}, \mathrm{La}, \mathrm{Nd}, \mathrm{THF}=\right.$ tetrahydrofuran, Scheme 3) by reacting the tris-allyl complexes $\mathrm{RE}\left(\eta^{3}-\mathrm{C}_{3} \mathrm{H}_{5}\right)_{3}$ (dioxane) described by Taube with one equivalent of $\left\{\left[\mathrm{HNMe}{ }_{2} \mathrm{Ph}\right]\left[\mathrm{B}\left(\mathrm{C}_{6} \mathrm{~F}_{5}\right)_{4}\right]\right\}$ in THF [21,22]. The monocationic bis-allyl analogues bearing a non-perfluorinated counteranion $\left[\mathrm{RE}\left(\eta^{3}-\mathrm{C}_{3} \mathrm{H}_{5}\right)_{2}(\mathrm{THF})_{3}\right]^{+}\left[\mathrm{BPh}_{4}\right]^{-}\left(\mathbf{1}_{\mathrm{RE}}{ }_{\mathrm{RE}}, \mathrm{RE}=\mathrm{Y}, \mathrm{La}, \mathrm{Nd}\right)$ were prepared similarly, but with $\left\{\left[\mathrm{HNEt}_{3} \mathrm{Ph}\right]\left[\mathrm{BPh}_{4}\right]\right\}$. In these complexes, the cationic allylic counterpart displays the same molecular structure as in complexes $\mathbf{1}_{\mathbf{R E}}$. X-ray crystal study of the monocationic yttrium complex $\mathbf{1}^{\prime} Y$ showed that all three allyl ligands are $\eta^{3}$ coordinated with similar bond lengths between each allyl ligand and yttrium metal. Crystals of $\mathbf{1}_{\mathbf{L a}}$ and $\mathbf{1}^{\prime}{ }_{\mathbf{N d}}$ were found to contain a fourth THF molecule, whereas elemental analysis was consistent with three-THF adducts after drying under vacuum. Two independent sets of ionic pairs were observed in $\mathbf{1}_{\mathbf{L a}}^{\prime}$ and $\mathbf{1}_{\mathbf{N d}}{ }_{\mathbf{d}}$, with allyl groups in a paddle-wheel fashion, or arranged as pincer-like towards each other. Shorter metal-allyl bonds were 
noticed by comparison with those of the parent compounds for both $\mathbf{1}_{\mathbf{L a}}{ }^{\prime}$ and $\mathbf{1}_{\mathbf{N d}}{ }_{\mathrm{N}}$, revealing a higher Lewis acidity of the rare earth metal from neutral to cationic species. The NMR (Nuclear Magnetic Resonance) analysis of complexes $\mathbf{1}_{\mathbf{Y}}$ and $\mathbf{1}_{\mathbf{Y}} \mathbf{Y}$ displayed two signals for the allyl group corresponding to fast syn/anti exchange on the NMR timescale. In contrast, three distinct signals were seen for $\mathbf{1}_{\mathbf{L a}}$ (and $\mathbf{1}_{\mathbf{L a}}$ ) and $\mathbf{1}_{\mathrm{Nd}}$ (and $\mathbf{1}_{\mathbf{N d}}$ ), typical of slow syn/anti exchange.
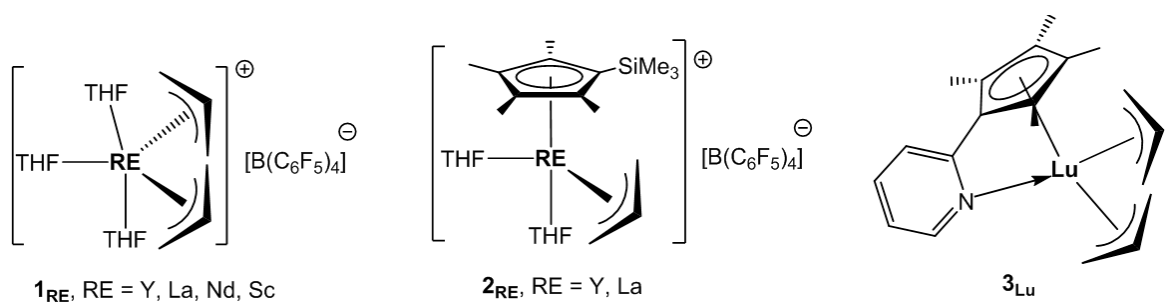

Scheme 3. Allylic rare earth complexes used for butadiene polymerization $[21,23,24]$.

The monocationic allyl complexes $\mathbf{1}_{\mathrm{RE}}$ showed no activity towards the polymerization of 1,3-butadiene at room temperature [21]. In contrast, these complexes were active when combined with $\mathrm{Al}\left({ }^{i} \mathrm{Bu}\right)_{3}$ as co-catalyst. The catalyst made from the yttrium complex $\mathbf{1}_{\mathbf{Y}}$ was found to be the most active (TOF 10,000 $\mathrm{h}^{-1}$ ) leading to the formation of PB with the highest 1,4-cis stereoregularity of $90 \%$ in comparison to those made from $\mathbf{1}_{\mathbf{L a}}$ and $\mathbf{1}_{\mathrm{Nd}}$ complexes (low yields and $33 \%$ and $75 \%$ of $1,4-$-cis units, respectively). This is a rare example that contradicts the well-known "neodymium effect" [6].

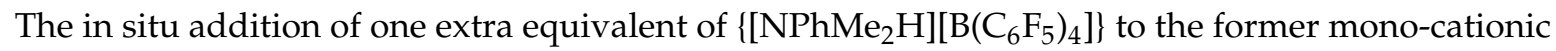
system in the polymerization mixture led to an increase in both the activity (up to TOF (Turn-Over Frequency) $12,000 \mathrm{~h}^{-1}$ ) and the selectivity with $92.5 \%$ of $1,4-c i s-\mathrm{PB}$ in the case of $\mathbf{1}_{\mathbf{Y}}$. However, the polymerizations carried out with $\mathbf{1}_{\mathbf{Y}}$ as precatalyst gave much broader dispersity, i.e., a less controlled process. Interestingly, the lanthanum-based precatalyst $\mathbf{1}_{\mathrm{La}}$ showed reverse stereo-selectivity when used with $\mathrm{Al}\left({ }^{i} \mathrm{Bu}\right)_{3}$ only and with the dual $\mathrm{Al}\left({ }^{i} \mathrm{Bu}\right)_{3} /\left\{\left[\mathrm{NPhMe}_{2} \mathrm{H}\right]\left[\mathrm{B}\left(\mathrm{C}_{6} \mathrm{~F}_{5}\right)_{4}\right]\right\}$ combination, switching from $63.3 \%$ 1,4-trans to $80.5 \%$ 1,4-cis-selectivity, respectively. The in situ formation of monoallyl dicationic species, as proposed by the authors, was likely to be responsible for the better reactivity. However, isolated $\left[\mathrm{RE}\left(\eta^{3}-\mathrm{C}_{3} \mathrm{H}_{5}\right)(\mathrm{THF})_{6}\right]^{2+}\left\{\left[\mathrm{B}\left(\mathrm{C}_{6} \mathrm{~F}_{5}\right)_{4}\right]^{-}\right\}_{2}(\mathrm{RE}=\mathrm{La}, \mathrm{Nd})$ from bulk scale syntheses were found to be rather unreactive.

The scandium congener $\left[\mathrm{Sc}\left(\eta^{3}-\mathrm{C}_{3} \mathrm{H}_{5}\right)_{2}(\mathrm{THF})_{3}\right]^{+}\left[\mathrm{B}\left(\mathrm{C}_{6} \mathrm{~F}_{5}\right)_{4}\right]^{-}\left(\mathbf{1}_{\mathrm{Sc}}\right)$ was prepared similarly as $\mathbf{1}_{\mathrm{RE}}$ $(\mathrm{RE}=\mathrm{Y}, \mathrm{La}, \mathrm{Nd})$ from the newly synthesized tris-allyl scandium, which was lacking in the family of analogous complexes of rare earths until Okuda and coworkers succeeded to isolate it [23]. Complex $\mathbf{1}_{\mathbf{S c}}$ could also be synthesized by reacting $\mathrm{K}\left[\mathrm{Sc}\left(\mathrm{C}_{3} \mathrm{H}_{5}\right)_{4}\right]$ with 2 equiv. $\left\{\left[\mathrm{HNEt}_{3}\right]\left[\mathrm{BPh}_{4}\right]\right\} .{ }^{1} \mathrm{H} \mathrm{NMR}$ analysis of $\mathbf{1}_{\mathrm{Sc}}$ revealed dynamic behavior of the allyl group while the crystallographic distances were typical of the $\eta^{3}$ coordination mode. This scandium allyl complex was assessed towards polymerization of 1,3-butadiene. When it was combined with 1 equiv. of $\mathrm{Al}\left({ }^{i} \mathrm{Bu}\right)_{3}$ as co-catalyst under similar conditions as for $\mathbf{1}_{\mathrm{RE}}(\mathrm{RE}=\mathrm{Y}, \mathrm{La}, \mathrm{Nd})$, it gave rise to a little amount of PB $\left(7 \%\right.$ yield, TOF $\left.280 \mathrm{~h}^{-1}\right)$ with low stereoregularity $(<60 \% 1,4-c i s)$. The activity was improved (TOF $\left.1150 \mathrm{~h}^{-1}\right)$ with the addition of one equivalent of $[\mathrm{HNMe} 2 \mathrm{Ph}]\left[\mathrm{B}\left(\mathrm{C}_{6} \mathrm{~F}_{5}\right)_{4}\right]$ in the polymerization mixture, but no change in the selectivity was observed.

The same research group synthesized the half-sandwich mono-allyl complexes $\left[\mathrm{RE}\left(\eta^{5}-\mathrm{C}_{5} \mathrm{Me}_{4} \mathrm{SiMe}_{3}\right)\left(\eta^{3}-\mathrm{C}_{3} \mathrm{H}_{5}\right)(\mathrm{THF})_{2}\right]^{+}\left[\mathrm{B}\left(\mathrm{C}_{6} \mathrm{~F}_{5}\right)_{4}\right]^{-}\left(2_{\mathrm{RE}}, \mathrm{RE}=\mathrm{Y}, \mathrm{La}\right.$, Scheme 3$)$ by protonation of the bis-allyl complexes $\mathrm{RE}\left(\eta^{5}-\mathrm{C}_{5} \mathrm{Me}_{4} \mathrm{SiMe}_{3}\right)\left(\eta^{3}-\mathrm{C}_{3} \mathrm{H}_{5}\right)_{2}(\mathrm{THF})$ with one equivalent of $\left\{\left[\mathrm{NPhMe}_{2} \mathrm{H}\right]\left[\mathrm{B}\left(\mathrm{C}_{6} \mathrm{~F}_{5}\right)_{4}\right]\right\}$ [21]. Little rigidity was noticed for the allyl group of $\mathbf{2}_{\mathrm{La}}$ by ${ }^{1} \mathrm{H} \mathrm{NMR}$, whereas $2_{Y}$ displayed higher fluxionality with fast syn/anti exchange. The activity of these mono-cationic complexes was screened towards the polymerization of 1,3-butadiene in the presence of $\left.\mathrm{Al}^{(}{ }^{i} \mathrm{Bu}\right)_{3}$ ( 5 equiv.) as a co-catalyst, since the complexes were found to be inactive on their own. The lanthanum system showed lower activity (TOF $1600 \mathrm{~h}^{-1}$ ), in comparison to the yttrium one which gave 
quantitative conversion for the same reaction time at room temperature in toluene (TOF $12,000 \mathrm{~h}^{-1}$ ) and moderate selectivity (86\% 1,4-cis).

Jian et al. prepared the pyridyl-functionalized half-sandwich of lutetium, $\left(\mathrm{C}_{5} \mathrm{Me}_{4}-\mathrm{C}_{5} \mathrm{H}_{4} \mathrm{~N}\right)$ $\mathrm{Lu}\left(\eta^{3}-\mathrm{C}_{3} \mathrm{H}_{5}\right)_{2} 3_{\mathrm{Lu}}$ by the clean protonolysis reaction of $\mathrm{Lu}\left(\eta^{3}-\mathrm{C}_{3} \mathrm{H}_{5}\right)_{3}$ (dioxane) with $\mathrm{C}_{5} \mathrm{Me}_{4} \mathrm{H}_{-}-\mathrm{C}_{5} \mathrm{H}_{4} \mathrm{~N}$ in THF [24]. The X-ray analysis showed that both allyl groups coordinate to the lutetium in a $\eta^{3}$ mode. Due to the coordination of the pyridyl moiety, the complex was isolated as solvent free. ${ }^{1} \mathrm{H}$ NMR displayed the typical 1 (quintet)/4 (doublet) set of signals for allyl groups in dynamic equilibrium. In combination with trityl borate activator, highly active catalyst towards butadiene polymerization was formed (TOF $60,000 \mathrm{~h}^{-1}$ ), which was also cis-1,4-selective up to $97 \%$. When chlorobenzene was used as the solvent, a drop in catalytic activity was noticed, but with the benefit of the stereo-conversion of cis-1,4 PB (99\%).

\section{Allyl Complexes for the Polymerization of Isoprene}

The coordination polymerization of isoprene can lead to the formation of polyisoprene (PI) containing four different isomers: 1,4-cis, 1,4-trans, 3,4-, and 1,2- (Scheme 2). Natural rubber extracted from the Hevea tree is composed predominantly of cis- units, whereas the one extracted from Gutta Percha is mainly trans-. Both cis-and trans-PI found numerous applications in the fields of adhesives, sports equipment, or the tire industry [25].

Cui, Hou, and co-workers explored constrained-geometry-conformation (CGC) allyl complexes of the rare earths as catalysts for isoprene polymerization [26]. They synthesized the aminophenyl-cyclopentadienyl complexes $\left(\mathrm{C}_{5} \mathrm{Me}_{4}-\mathrm{C}_{6} \mathrm{H}_{4}-o-\mathrm{NMe}_{2}\right) \mathrm{RE}\left(\eta^{3}-\mathrm{C}_{3} \mathrm{H}_{5}\right)_{2}\left(4_{\mathrm{RE}}, \mathrm{RE}=\mathrm{Y}, \mathrm{Nd}\right.$, Gd, Dy, Scheme 4) by first reacting $\left(\mathrm{C}_{5} \mathrm{Me}_{4}-\mathrm{C}_{6} \mathrm{H}_{4}-o-\mathrm{NMe}_{2}\right) \mathrm{Li}$ with $\mathrm{RECl}_{3}(\mathrm{THF})_{n}$ and then adding the Grignard reagent, $\mathrm{C}_{3} \mathrm{H}_{5} \mathrm{MgCl}$. By ${ }^{1} \mathrm{H}$ NMR, the allyl group in $\mathbf{4}_{\mathbf{Y}}$ was found fluxional with the typical $1 \mathrm{H} / 4 \mathrm{H}$ resonances. The yttrium, gadolinium, and dysprosium complexes were characterized by X-ray crystallography as solvent-free-even though the reaction was performed in THF solvent-isostructural complexes and it showed that both allyl moieties coordinate in the $\eta^{3}$ mode. The activity of these bis(allyl) complexes was assessed towards the polymerization of isoprene in the presence of $\mathrm{AlR}_{3}$ (mainly $\left.\mathrm{Al}\left({ }^{i} \mathrm{Bu}\right)_{3}\right)$ and $\left\{\left[\mathrm{PhMe}_{2} \mathrm{NH}\right]\left[\mathrm{B}\left(\mathrm{C}_{6} \mathrm{~F}_{5}\right)_{4}\right]\right\}$ in toluene at $20^{\circ} \mathrm{C}$. The neodymium complex $4_{\mathrm{Nd}}$ had the highest activity (TOF $\left.3000 \mathrm{~h}^{-1}\right)$, followed by the gadolinium $4_{\mathrm{Gd}}\left(1000 \mathrm{~h}^{-1}\right.$ ) and then the dysprosium $4_{\mathrm{Dy}}$ analogue $\left(110 \mathrm{~h}^{-1}\right)$. The yttrium complex $4_{\mathrm{Y}}$ was almost inert towards this polymerization under these conditions, while low to medium activity (TOF 140-800 $\mathrm{h}^{-1}$ ) was noticed with $\left\{\left[\mathrm{Ph}_{3} \mathrm{C}\right]\left[\mathrm{B}\left(\mathrm{C}_{6} \mathrm{~F}_{5}\right)_{4}\right]\right\} / \mathrm{AlR}_{3}\left(\mathrm{R}=\mathrm{Me}, \mathrm{Et},{ }^{i} \mathrm{Bu}\right)$. The gadolinium complex $\mathbf{4}_{\mathrm{Gd}}$ afforded the highest cis-regular PI at $99.2 \%$ (at $0{ }^{\circ} \mathrm{C}$ ), along with the living character of the polymerization. It was observed that when the $\mathrm{Al} / \mathrm{Gd}$ ratio was increased, a typical catalyzed chain growth (CCG) process was operating, with regular decrease of the molecular weight of the PI while the molecular weight distribution remained unchanged. $\mathrm{Al}\left({ }^{i} \mathrm{Bu}\right)_{3}$ behaved partially as a chain transfer agent, with ca. eight growing PI chains per RE metal, while no drop of stereo-selectivity was evident (ca. 98\% cis-units).
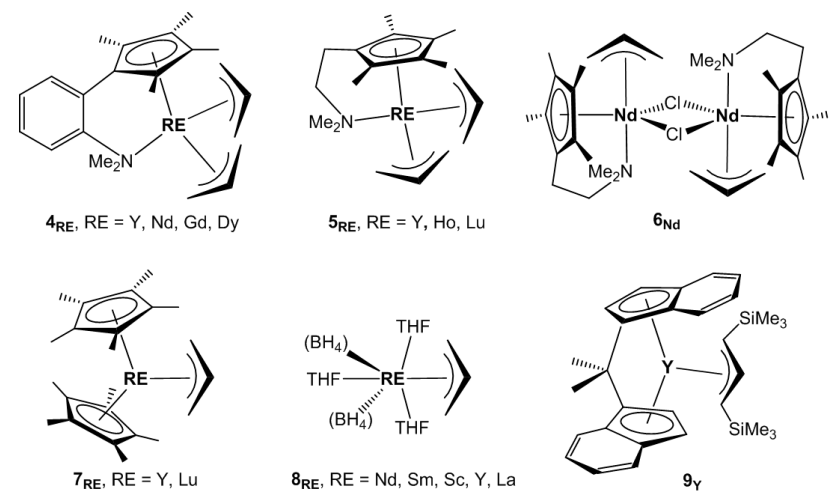

Scheme 4. Allylic rare earth complexes used for isoprene polymerization [26-31]. 
Jende et al. synthesized the allyl half-sandwich complexes of small-size rare earths, $\mathrm{Cp}^{\mathrm{NMe} 2} \mathrm{RE}\left(\eta^{3}-\mathrm{C}_{3} \mathrm{H}_{5}\right)_{2}\left(\mathrm{Cp}^{\mathrm{NMe} 2}=\mathrm{C}_{5} \mathrm{Me}_{4} \mathrm{CH}_{2} \mathrm{CH}_{2} \mathrm{NMe}_{2} ; 5_{\mathrm{RE}}, \mathrm{RE}=\mathrm{Y}, \mathrm{Ho}, \mathrm{Lu}\right.$, Scheme 4) having a more flexible ( $N, N$-dimethylamino)ethyl-functionalized cyclopentadienyl ligand than in the $4_{\mathrm{RE}}$ complexes [27]. The reaction was conducted in two steps by first reacting $\mathrm{RECl}_{3}(\mathrm{THF})_{\mathrm{x}}$ with $\mathrm{Cp}^{\mathrm{NMe} 2} \mathrm{Li}$ at room temperature, and then adding two equivalents of the Grignard reagent $\mathrm{C}_{3} \mathrm{H}_{5} \mathrm{MgCl}$. X-ray analysis showed that the $5_{\mathrm{RE}}$ complexes were under a bis(allyl) half-sandwich monomeric form, and were all isostructural. One of the allyl groups showed similar bond lengths between terminal and central carbon atoms, while the second allyl group showed a significantly longer bond length between the rare earth metal and the terminal carbon. The overall moiety arrangement was likened to that of $4_{Y}$ [26]. The ${ }^{1} \mathrm{H}$ NMR of both diamagnetic complexes $5_{Y}$ and $5_{L u}$ showed a similar quintet $(1 \mathrm{H}) /$ doublet $(4 \mathrm{H})$ set of signals characteristic of dynamic exchange of the allylic protons, along with splitting of the quintet in the case of $5_{Y}$ being attributable to the coupling with ${ }^{89} \mathrm{Y}$. When the same synthetic procedure as for $5_{\mathrm{RE}}$ was done in the case of the larger size neodymium element, it gave a monoallyl chloro derivative $\left[\mathrm{Cp}^{\mathrm{NMe} 2} \mathrm{Nd}\left(\eta^{3}-\mathrm{C}_{3} \mathrm{H}_{5}\right)(\mu-\mathrm{Cl})\right]_{2}\left(\mathbf{6}_{\mathrm{Nd}}\right.$, Scheme 4$)$ instead of the expected bis allyl half-sandwich. Complex $\mathbf{6}_{\mathrm{Nd}}$ was found to be dimeric through $(\mu-\mathrm{Cl})$ bridges with one substantially longer $\mathrm{Nd}-\mathrm{Cl}$ bond than the other one, anticipating a possible reactivity. [Allyl]/[Cl] exchange was observed when complexes $5_{Y}$ and $5_{\mathrm{Ho}}$ were reacted with $\mathrm{AlEt}{ }_{2} \mathrm{Cl}$, affording multi $\left(\mu\right.$-chlorido) hexametallic $\left[\mathrm{RE}_{6} \mathrm{Cl}_{12}\right]$ clusters. This was in agreement with the observation that the combination of any $5_{\mathrm{RE}}$ with $\mathrm{AlEt}_{2} \mathrm{Cl}$ was found inert towards isoprene polymerization.

When activated with either $\left\{\left[\mathrm{Ph}_{3} \mathrm{C}\right]\left[\mathrm{B}\left(\mathrm{C}_{6} \mathrm{~F}_{5}\right)_{4}\right]\right\}$ or $\left\{\left[\mathrm{PhNMe}_{2} \mathrm{H}\right]\left[\mathrm{B}\left(\mathrm{C}_{6} \mathrm{~F}_{5}\right)_{4}\right]\right\}$ borates, the half-sandwiches $5_{Y}$ and $5_{\mathrm{Ho}}$ were found to be poorly active (TOF $100 \mathrm{~h}^{-1}$ ) towards the polymerization of isoprene, while $5_{\mathrm{Lu}}$ displayed higher activity (TOF $500 \mathrm{~h}^{-1}$ ). The yttrium $\left(5_{\mathbf{Y}}\right)$ and holmium $\left(5_{\mathbf{H o}}\right)$ complexes afforded predominantly 3,4-PI with both co-catalysts. The lutetium complex $5_{\mathrm{Lu}}$ afforded non stereo-regular PI. The dispersities were very narrow (1.04-1.17) for all the precatalysts used, accounting for unique active species. In addition, in the presence of 10 equiv. $\mathrm{AlMe}_{3}$, the $5_{\mathrm{Y}} /$ borate and $5_{\mathrm{Ho}} /$ borate combinations afforded much more active catalysts (TOF up to $\left.2000 \mathrm{~h}^{-1}\right)$ with a switch in selectivity towards trans-1,4 selectivity $(71 \% \mathrm{Y}, 72 \% \mathrm{Ho})$. In contrast, when 10 equiv. $\mathrm{Al}^{i} \mathrm{Bu}_{3}$ were added to the $5_{\mathbf{Y}} /$ borate and $5_{\mathbf{H o}} /$ borate systems, it afforded a major selectivity towards cis-1,4 PI (74\% Y, 74\% Ho) along with improved activity (TOF $\left.1000 \mathrm{~h}^{-1}\right)$. For the lutetium complex $5_{\mathbf{L u}}$, when $\mathrm{AlMe}_{3}$ or $\mathrm{Al}\left({ }^{i} \mathrm{Bu}\right)_{3}$ was added to the system the main effect was a similar gain of activity (TOF up to $2000 \mathrm{~h}^{-1}$ ), but with no improvement of the stereocontrol. A decrease in the polymer molecular weights with narrow distributions was also noticed, which indicated a chain transfer to aluminum. The activity of the chloroallyl neodymium complex $\mathbf{6}_{\mathrm{Nd}}$ was also assessed towards the polymerization of isoprene with the use of either $\left\{\left[\mathrm{Ph}_{3} \mathrm{C}\right]\left[\mathrm{B}\left(\mathrm{C}_{6} \mathrm{~F}_{5}\right)_{4}\right]\right\}$ or $\left\{\left[\mathrm{PhNMe}{ }_{2} \mathrm{H}\right]\left[\mathrm{B}\left(\mathrm{C}_{6} \mathrm{~F}_{5}\right)_{4}\right]\right\}$ as a borate activator. There was no activity when the $[\mathrm{Nd}]$ :[borate] ratio was 1:1. However, when 1 equiv. of activator was added to the dinuclear complex ([Nd]:[borate] is 2:1), PI, with mainly 3,4-motives of up to $66 \%$, was isolated with good activity (TOF $500 \mathrm{~h}^{-1}$ ), along with narrow dispersities (1.10-1.11). When 10 equiv. of $\mathrm{AlMe}_{3}$ was added to the system along with $\left\{\left[\mathrm{PhNMe}_{2} \mathrm{H}\right]\left[\mathrm{B}\left(\mathrm{C}_{6} \mathrm{~F}_{5}\right)_{4}\right]\right\}$, there was a switch in stereo-selectivity and trans-1,4-PI $(85 \%)$ was obtained, while the addition of $\mathrm{Al}\left({ }^{i} \mathrm{Bu}\right)_{3}$ (10 equiv.) gave rise to 3,4-PI (85\%). The activity was improved by a factor of four (TOF $2000 \mathrm{~h}^{-1}$ ) and of two (TOF $1000 \mathrm{~h}^{-1}$ ) by the addition of $\mathrm{AlMe}_{3}$ and $\mathrm{AliBu}_{3}$, respectively. In all cases with complexes bearing this $\mathrm{Cp}^{\mathrm{NMe} 2}$ ligand $\left(\mathbf{5}_{\mathrm{RE}}\right.$ and $\left.\mathbf{6}_{\mathrm{Nd}}\right)$, the use of $\mathrm{AliBu}_{3}$ vs. $\mathrm{AlMe}_{3}$ provided reversible transfer between the RE metal and the aluminum during the polymer chain growing process. Allyl(RE)-alkyl(Al) exchange was evidenced by ${ }^{1} \mathrm{H}$ NMR experiments to support the formation of the polymerization active species. None of these allyl complexes $\mathbf{5}_{\mathrm{RE}}$ and $\mathbf{6}_{\mathrm{Nd}}$ were found active on their own without activator/co-catalyst.

The photopolymerization of isoprene mediated by $\left(\mathrm{C}_{5} \mathrm{Me}_{5}\right)_{2} \mathrm{RE}\left(\eta^{3}-\mathrm{C}_{3} \mathrm{H}_{5}\right)\left(7_{\mathrm{RE}}, \mathrm{RE}=\mathrm{Y}, \mathrm{Lu}\right.$, Scheme 4) was assessed [28]. These complexes had been previously synthesized and characterized [13]. In particular, the ${ }^{1} \mathrm{H}$ NMR analysis established non-fluxional allyl group with $1 \mathrm{H} / 2 \mathrm{H} / 2 \mathrm{H}$ allyl signals. In neat monomer, the reaction resulted in obtaining low molecular weight PI with 3,4-units being 
slightly predominant, which was consistent with radical polymerization, according to the authors. In the absence of irradiation, no polymerization was observed with the yttrium complex $7_{\mathbf{Y}}$.

Bonnet, Visseaux, and co-workers synthesized the first RE complexes bearing both allyl and borohydride ligands, $\mathrm{RE}\left(\mathrm{BH}_{4}\right)_{2}\left(\eta^{3}-\mathrm{C}_{3} \mathrm{H}_{5}\right)(\mathrm{THF})_{3}\left(8_{\mathrm{RE}}, \mathrm{RE}=\mathrm{Nd}, \mathrm{Sm}\right.$, Scheme 4$)$ by reacting $\mathrm{RE}\left(\mathrm{BH}_{4}\right)_{3}(\mathrm{THF})_{3}$ with half an equivalent of $\mathrm{Mg}\left(\mathrm{C}_{3} \mathrm{H}_{5}\right)_{2}(\mathrm{~L})_{n}(\mathrm{~L}=\mathrm{THF}$, dioxane) in THF at room temperature [29]. From ${ }^{1} \mathrm{H}$ NMR analysis, the allyl moiety appeared as a $1 \mathrm{H} / 2 \mathrm{H} / 2 \mathrm{H}$ set of resonances for both $8_{\text {RE }}$ complexes, revealing no dynamic behavior at the ${ }^{1} \mathrm{H}$ NMR timescale. X-ray analyses showed that both complexes were monomeric and isostructural, with the two borohydride ligands being tridentate. The activity of these mixed borohydrido-allyl rare earth complexes $\mathrm{RE}\left(\mathrm{BH}_{4}\right)_{2}\left(\eta^{3-} \mathrm{C}_{3} \mathrm{H}_{5}\right)(\mathrm{THF})_{3}$ was assessed towards the polymerization of isoprene. Whereas the samarium complex showed no reactivity, its neodymium analogue was found to be active, either on its own, due to the presence of the Nd-allyl bond, or combined with various alkylating reagents. When the latter was tested alone, highly trans-regular PI with $92.2 \%$ trans-selectivity along with $Đ$ $=1.54$ was obtained with moderate activity (TOF $177 \mathrm{~h}^{-1}$ ). In the presence of one equivalent of $\mathrm{Mg}\left({ }^{n} \mathrm{Bu}\right)(\mathrm{Et})$ with respect to $8_{\mathrm{Nd}}$, the activity was substantially increased (TOF $425 \mathrm{~h}^{-1}$ ), but also the trans-selectivity of the reaction was improved $(95.5 \%$ trans). With aluminum-based co-catalysts, such as $\mathrm{Al}\left({ }^{i} \mathrm{Bu}\right)_{3}$ or MAO (MethylAlumOxane), the activities were greatly improved with TOF of $1000 \mathrm{~h}^{-1}$, however, the trans-selectivity was affected $(78.7 \%$ and $68.2 \%$, respectively). This family of complexes was recently extended to scandium (bis-THF adduct), yttrium, and lanthanum [30].

The ansa-lanthanidocene allyl rac- $\left\{\mathrm{Me}_{2} \mathrm{C}(\mathrm{Ind})_{2}\right\} \mathrm{Y}\left[\eta^{3}-1,3-\left(\mathrm{SiMe}_{3}\right)_{2} \mathrm{C}_{3} \mathrm{H}_{3}\right]\left(\mathbf{9}_{\mathrm{Y}}\right)$ (Ind = 2-indenyl) was assessed for the polymerization of isoprene [32]. This compound was synthesized previously and initially evaluated for styrene polymerization as single-component catalyst [31]. Towards isoprene, and again in the absence of co-reagent, complex $\mathbf{9}_{\mathbf{Y}}$ afforded 1,4-trans PI (87-91\%) with moderate activity $\left(\mathrm{TOF} 70 \mathrm{~h}^{-1}\right.$ ). It is noteworthy that, up to now, this is the unique example of a single-component yttrium catalyst for the trans-stereo-selective polymerization of isoprene. With di(ethyl)zinc in excess, it was established that reversible $\mathrm{Y} / \mathrm{Zn}$ chain transfer was operating, with a comparable activity (TOF $76 \mathrm{~h}^{-1}$ ), while maintaining the 1,4-trans selectivity (ca. 90\%). In turn, the polymerization of isoprene mediated by $9_{\mathrm{Y}} / \mathrm{Mg}\left({ }^{n} \mathrm{Bu}\right)_{2}$ occurred with a good level of transfer, but at the expense of the 1,4-trans selectivity (up to $47 \% 3,4$ units).

\section{Allyl Complexes for the Polymerization of Styrene}

Polystyrene (PS) is a thermoplastic polymer mostly known for its applications in long-lasting packaging. Styrene, when polymerized by coordination-insertion polymerization, can give rise to PS under three different forms: isotactic, syndiotactic, or atactic (Scheme 5).

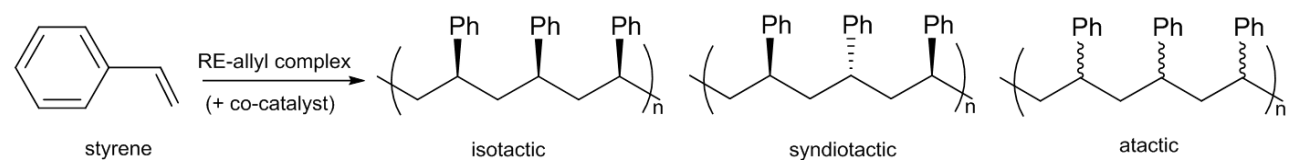

Scheme 5. Polymerization of styrene by means of RE(allyl)-based catalysts.

The scandium bis-allyl mono-cationic complex $\left[\mathrm{Sc}\left(\eta^{3}-\mathrm{C}_{3} \mathrm{H}_{5}\right)_{2}(\mathrm{THF})_{3}\right]^{+}\left[\mathrm{B}\left(\mathrm{C}_{6} \mathrm{~F}_{5}\right)_{4}\right]^{-}\left(\mathbf{1}_{\mathrm{Sc}}\right)$, which was proved to be efficient towards butadiene polymerization when combined with $\left.\mathrm{Al}^{(}{ }^{i} \mathrm{Bu}\right)_{3}$ and $\left\{\left[\mathrm{HNMe}_{2} \mathrm{Ph}\right]\left[\mathrm{B}\left(\mathrm{C}_{6} \mathrm{~F}_{5}\right)_{4}\right]\right\}$ (see above) was also studied for styrene polymerization. It was found to be inactive in this case as a single component, while displaying low activity in the presence of $\mathrm{Al}\left({ }^{i} \mathrm{Bu}\right)_{3}$ (TOF up to $95 \mathrm{~h}^{-1}$ ) to afford atactic PS. The addition of $\left\{[\mathrm{HNMe} 2 \mathrm{Ph}]\left[\mathrm{B}\left(\mathrm{C}_{6} \mathrm{~F}_{5}\right)_{4}\right]\right\}$ as activator did not really improve the catalysis (atactic PS, TOF $114 \mathrm{~h}^{-1}$ ) [23]. 

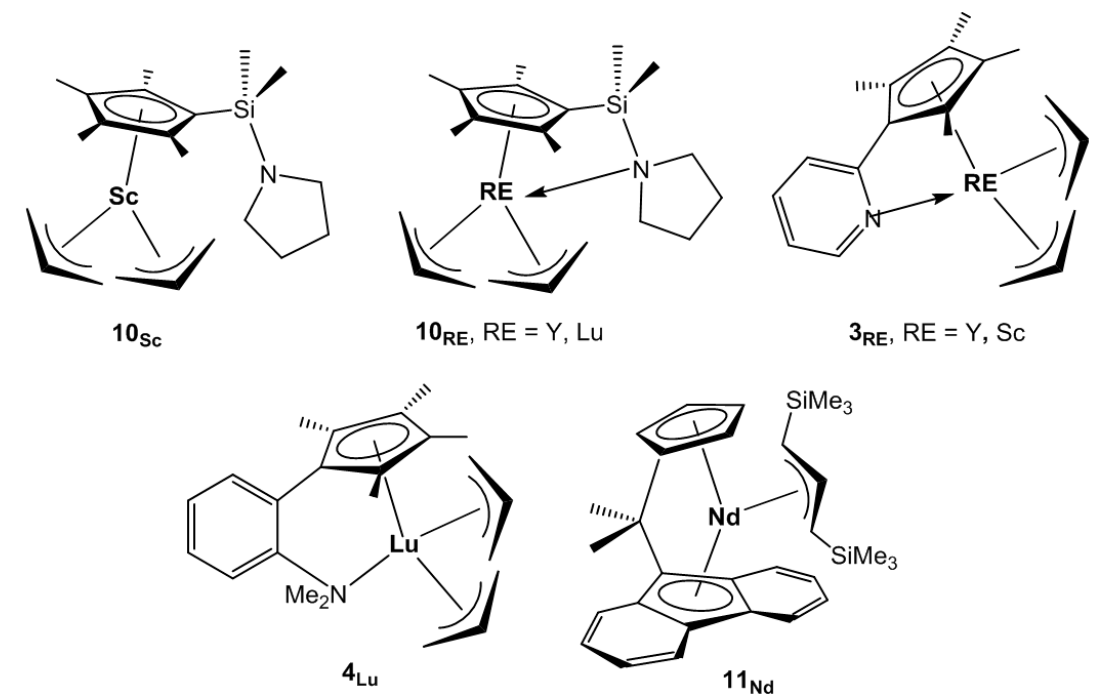

Scheme 6. Allylic rare earth complexes used for styrene polymerization [33-35].

The pyrrolidinyl-functionalized half-sandwich complexes $\left(\mathrm{C}_{5} \mathrm{Me}_{4} \mathrm{SiMe}_{2} \mathrm{NC}_{4} \mathrm{H}_{8}\right) \mathrm{RE}\left(\eta^{3}-\mathrm{C}_{3} \mathrm{H}_{5}\right)_{2}$ $\left(\mathbf{1 0}_{\mathrm{RE}}, \mathrm{RE}=\mathrm{Sc}, \mathrm{Y}, \mathrm{Lu}\right.$, Scheme 6) were synthesized by reacting $\mathrm{RECl}_{3}$ with one equivalent of $\mathrm{C}_{5} \mathrm{Me}_{4} \mathrm{SiMe}_{2}-\mathrm{NC}_{4} \mathrm{H}_{8} \mathrm{Li}$ followed by the addition of two equivalents of $\mathrm{C}_{3} \mathrm{H}_{5} \mathrm{MgCl}$ in THF at room temperature [33]. The ${ }^{1} \mathrm{H}$ NMR spectra of the three complexes indicated the fluxional allyl ligand in solution, with one sharp doublet signal for the terminal allylic protons and one multiplet for the central allylic protons. X-ray analysis showed that for the scandium complex $\mathbf{1 0}_{\mathrm{Sc}}$, the pendant pyrrolidinyl ligand does not coordinate to the metal center through the nitrogen, whereas this coordination was present in the yttrium $10_{\mathrm{Y}}$ and lutetium $10_{\mathrm{Lu}}$ complexes due to higher size of the $\mathrm{RE}^{3+}$ cation [36]. In $10_{\mathrm{Sc}}$, the two allyl moieties were coordinated to the central metal in $\eta^{3}$ mode with one allyl group prone and the other supine. The half sandwich complex $10_{\mathrm{Sc}}$ was found to be highly active towards styrene polymerization when activated with one equivalent of $\left\{\left[\mathrm{Ph}_{3} \mathrm{C}\right]\left[\mathrm{B}\left(\mathrm{C}_{6} \mathrm{~F}_{5}\right)_{4}\right]\right\}$ in toluene at room temperature, producing pure syndiotactic PS (TOF $250 \mathrm{~h}^{-1}$ ). Yttrium complex $10_{\mathrm{Y}}$ was much less active $\left(70 \mathrm{~h}^{-1}\right)$ while $10_{\mathrm{Lu}}$ only produced traces of the polymer under the same conditions. When an excess of $\mathrm{Al}\left({ }^{i} \mathrm{Bu}\right)_{3}$ was added to $1_{\mathrm{Sc}} /\left\{\left[\mathrm{Ph}_{3} \mathrm{C}\right]\left[\mathrm{B}\left(\mathrm{C}_{6} \mathrm{~F}_{5}\right)_{4}\right]\right\}$, the activity increased drastically (TOF $1500 \mathrm{~h}^{-1}$ ).

The pyridyl-functionalized half-sandwich complexes $\left(\mathrm{C}_{5} \mathrm{Me}_{4}-\mathrm{C}_{5} \mathrm{H}_{4} \mathrm{~N}\right) \mathrm{RE}\left(\eta^{3}-\mathrm{C}_{3} \mathrm{H}_{5}\right)_{2}\left(3_{\mathrm{RE}}, \mathrm{RE}=\mathrm{Y}\right.$, Sc, Scheme 6), analogs of complex $3_{\mathrm{Lu}}$, were prepared. The syntheses were conducted by metathetic reaction of $\left(\mathrm{C}_{5} \mathrm{Me}_{4}-\mathrm{C}_{5} \mathrm{H}_{4} \mathrm{~N}\right) \mathrm{Li}$ with 1 equiv. $\mathrm{RECl}_{3}$, followed by addition of 2 equiv. allyl $\mathrm{MgCl}$ in THF at room temperature [35]. Alternatively, the target compounds could be also obtained by the acid base reaction between $\mathrm{RE}\left(\mathrm{C}_{3} \mathrm{H}_{5}\right)_{3}$ (1,4-dioxane) and the pyridyl-cyclopentadiene $\mathrm{C}_{5} \mathrm{Me}_{4} \mathrm{H}_{-} \mathrm{C}_{5} \mathrm{H}_{4} \mathrm{~N}$, as same as previously done for $3_{\mathrm{Lu}}$. The $\mathrm{X}$-ray structure displayed the expected CGC-geometry with $\eta^{5}(\mathrm{Cp}) / \mathcal{K}^{1}(\mathrm{Py})$ coordination to the RE center. In contrast to what was observed in complexes $2_{Y}$ [21] and $4_{Y}[26]$, the ${ }^{1} \mathrm{H}$ NMR of $3_{Y}$ displayed a $1 \mathrm{H} / 2 \mathrm{H} / 2 \mathrm{H}$ pattern resonances for the allyl ligands, thus suggesting poor fluxionality in solution, while in the case of $33_{\mathrm{sc}}$ only two allyl signals $(1 \mathrm{H} / 4 \mathrm{H})$ were observed. In combination with $\left\{\left[\mathrm{Ph}_{3} \mathrm{C}\right]\left[\mathrm{B}\left(\mathrm{C}_{6} \mathrm{~F}_{5}\right)_{4}\right]\right\}$ in toluene, complex $3_{\mathrm{Y}}$ showed moderate activity (TOF $120 \mathrm{~h}^{-1}$ ) but syndiotactic enriched PS $(r r r r=88 \%)$. This catalytic system made of yttrium was much more active in chlorobenzene (TOF $2000 \mathrm{~h}^{-1}$ ) but less stereoselective. In turn, the scandium analogue $3_{\mathrm{sc}}$ was found to display under the same conditions exceptionally high performances affording PS perfectly syndiotactic ( $r r r r>99 \%)$ with TOF value of $60,000 \mathrm{~h}^{-1}$ (complete conversion of 1000 equivalents of monomer in $1 \mathrm{~min}$ at $20^{\circ} \mathrm{C}$ in toluene) [37] and narrow dispersity $(Đ=1.40-1.50)$. However, lower activity/selectivity was noticed in chlorobenzene for $3 \mathrm{Sc}$. Although the process was less controlled $(Đ=1.94)$, the lutetium complex $3_{\mathrm{Lu}}$ gave the same notable results as $3_{\mathrm{Sc}}$ in terms of catalytic capability, and remarkably, the former complex exhibited a rare dual catalysis ability $[24,38]$ in both syndiotactic styrene polymerization and cis-selective butadiene 
polymerization. Contrary to what advanced for $4_{\mathbf{L u}}$, the smaller $\mathrm{Cp}_{\text {cent }}-\mathrm{RE}-\mathrm{N}$ bite angle in pyridyl-Cp complexes $3_{\mathrm{RE}}$, along with a more electron withdrawing effect of the ligand, was proposed to explain the catalytic efficiency of the latter complexes.

Cui, Hou, and co-workers extended the family of constrained geometry catalysts $4_{\mathrm{RE}}$ [26] to the lutetium derivative $\left(\mathrm{C}_{5} \mathrm{Me}_{4}-\mathrm{C}_{6} \mathrm{H}_{4}-o-\mathrm{NMe}_{2}\right) \mathrm{Lu}\left(\eta^{3}-\mathrm{C}_{3} \mathrm{H}_{5}\right)_{2}\left(4_{\mathrm{Lu}}\right.$, Scheme 6), by a synthetic procedure similar to that used for the latter complexes [35]. Upon activation of this lutetium complex with $\left\{\left[\mathrm{Ph}_{3} \mathrm{C}\right]\left[\mathrm{B}\left(\mathrm{C}_{6} \mathrm{~F}_{5}\right)_{4}\right]\right\}$, or with the $\left\{\left[\mathrm{Ph}_{3} \mathrm{C}\right]\left[\mathrm{B}\left(\mathrm{C}_{6} \mathrm{~F}_{5}\right)_{4}\right]\right\} / \mathrm{Al}\left({ }^{i} \mathrm{Bu}\right)_{3}$ combination, the product was inert for the polymerization of styrene. The same was observed for $4_{Y}$ under the same conditions. According to the authors, this could be due to the large $C \mathrm{p}_{\text {cent }}-\mathrm{Lu}-\mathrm{N}$ bite angle in $4_{\mathrm{RE}}$, in comparison with the value determined in complexes $3_{\mathrm{RE}}$, which hinders the coordination and insertion of the styrene monomer.

Carpentier and colleagues found that the combination of bulky allyl ansa-lanthanidocenes rac- $\left\{\mathrm{Me}_{2} \mathrm{C}(\mathrm{Ind})_{2}\right\} \mathrm{Y}\left[\eta^{3}-1,3-\left(\mathrm{SiMe}_{3}\right)_{2} \mathrm{C}_{3} \mathrm{H}_{3}\right]\left(\mathbf{9}_{\mathbf{Y}}\right)$ and $\left\{\mathrm{Me}_{2} \mathrm{C}(\mathrm{Cp})(\mathrm{Flu})\right\} \mathrm{Nd}\left[\eta^{3}-1,3-\left(\mathrm{SiMe}_{3}\right)_{2} \mathrm{C}_{3} \mathrm{H}_{3}\right]\left(\mathbf{1 1}_{\mathrm{Nd}}\right)$ (Flu = 9-fluorenyl, Scheme 6) with di(n-butyl)magnesium in excess behaved efficiently as binary catalytic systems for the stereo-controlled coordinative polymerization of styrene under reversible chain transfer regime (CCTP, coordinative chain transfer polymerization). Isotactic PS was produced with $9_{\mathbf{Y}} / \mathrm{Mg}\left({ }^{n} \mathrm{Bu}\right)_{2}$ while $11_{\mathrm{Nd}} / \mathrm{Mg}\left({ }^{n} \mathrm{Bu}\right)_{2}$ yielded syndiotactic PS, both with high activities (TOF up to $2100 \mathrm{~h}^{-1}$ and $2500 \mathrm{~h}^{-1}$, respectively [34]. By adjusting the amount of $\mathrm{Mg}\left({ }^{n} \mathrm{Bu}\right)_{2}$, up to 200 polymer chains can be generated per RE center. Complex $9_{Y}$ was previously shown to be active as a single-component catalyst [32], but the dispersity was improved in the presence of excess $\mathrm{Mg}\left({ }^{n} \mathrm{Bu}\right)_{2}$. Mechanistic investigations, also confirmed by the support of theoretical studies, demonstrated that the initiation of the polymerization resulted from the insertion of styrene into the RE-allyl (single component) or RE-alkyl (chain transfer) moiety, and that an enantiomorphic site control mechanism (ECM) was operative to account for the isoselectivity observed [39]. As for the ansa derivative $\mathbf{1 1}_{\mathbf{N d}}$, it was synthesized by ionic metathesis between $\mathrm{K}[1,3-(\mathrm{SiMe} 3) 2 \mathrm{C} 3 \mathrm{H} 3]$ and $\left[\left\{\mathrm{Me}_{2} \mathrm{C}(\mathrm{Cp})(\mathrm{Flu})\right\} \mathrm{Nd}(\mu-\mathrm{Cl})\right]_{2}$ and was found unsolvated. It was shown that $\mathbf{1 1}_{\mathbf{N d}}$ acts as a single-component catalyst for the polymerization of styrene, and produces $s$ PS albeit at a much lower rate $\left(\mathrm{TOF}=20-60 \mathrm{~h}^{-1}\right)$ than the regular allyl compounds $\left\{\mathrm{Me}_{2} \mathrm{C}(\mathrm{Cp})(\mathrm{Flu})\right\} \mathrm{RE}\left(\eta^{3}-\mathrm{C}_{3} \mathrm{H}_{5}\right)(\mathrm{THF})\left(\mathrm{RE}=\mathrm{Y}, \mathrm{La}, \mathrm{Nd}, 1000-17,000 \mathrm{~h}^{-1}\right)$ [40]. Using DFT (Density Functional Theory) studies, the origin of the syndiospecificity control, due to a chain-end control mechanism (CEM), was proposed to result from the conjunction of the minimization of two repulsion effects: the classical phenyl (incoming monomer)-phenyl (last unit inserted) one during the growing of the polymer chain, and also of the repulsion between the fluorenyl ligand and the incoming styrene unit [41].

\section{Allyl Complexes for Co-Polymerization}

Since 2010, very few reports dealt with the copolymerization of dienes/styrene monomers involving allyl derivatives of the rare earths.

Complex $3_{\mathrm{Lu}}$, which was found efficient as a precatalyst towards butadiene and styrene homopolymerization (see above), was assessed successfully for the copolymerization of these two monomers. When combined with trityl borate, the resulting catalyst system showed high activity (TOF up to $5100 \mathrm{~h}^{-1}$ ) for the statistical and the sequenced copolymerization of butadiene and styrene. The concurrent addition of both the monomers with the styrene feed molar fractions ranging from 10-90\%, afforded highly cis-1,4-regulated PB and syndiotactic PS segments, high molecular weight $\left(M_{\mathrm{n}}=8.8-12.1 \times 10^{4} \mathrm{~g} \mathrm{~mol}^{-1}\right)$ and narrow dispersity (1.29-1.68) across the styrene feed ratio range. Kinetic studies demonstrated that in the presence of a mixture of the two monomers butadiene was consumed first, followed by the growing of the syndiotactic PS sequence, finally affording diblock styrene-butadiene copolymers in all cases. The same kind of copolymer was isolated from sequenced butadiene/styrene copolymerization. These copolymers displayed a phase separated morphology of the hard (sPS) and soft (cis-PBu) domains, as observed by atomic force microscopy [24].

Upon activation with $\left\{\left[\mathrm{Ph}_{3} \mathrm{C}\right]\left[\mathrm{B}\left(\mathrm{C}_{6} \mathrm{~F}_{5}\right)_{4}\right]\right\} / \mathrm{Al}\left({ }^{i} \mathrm{Bu}\right)_{3},\left(\mathrm{C}_{5} \mathrm{Me}_{4}-\mathrm{C}_{6} \mathrm{H}_{4}-o-\mathrm{NMe}_{2}\right) \mathrm{RE}\left(\eta^{3}-\mathrm{C}_{3} \mathrm{H}_{5}\right)_{2}\left(4_{\mathrm{Gd}}\right)$ afforded via sequential monomer addition unprecedented cis-PI-b-cis-PB and cis-PI-b-cis-PB-b-cis-PI 
block copolymers. This was possible thanks to the living polymerization process occurring through reversible $\mathrm{Gd} / \mathrm{Al}$ chain transfer [26].

The allyl ansa complex $9_{\mathrm{Y}}$ showed unique behavior to produce isoprene-styrene copolymers. Polymerizations experiments were conducted in one pot in the absence of co-reagent and afforded copolymers with blocky distribution of the two monomers. Unprecedented well-defined and crystalline 1,4-trans-PI- $b$-iPS diblock copolymers were also prepared by sequential addition of the two monomers [31].

\section{Concluding Remarks}

In the last eight years, a number of new allyl rare earth complexes have been synthesized and assessed towards the (co-)polymerization of non-polar monomers (Table 1). It must be noted that when browsing through the recent reports of the field gathered in this review, it appears that the utilization of such compounds for polymerization is limited to conjugated dienes and styrene, while none deal with ethylene, although allyl species of the rare earths are known to mediate the polymerization of that latter monomer $[3,6]$.

In some cases towards conjugated dienes or styrene, an allyl rare earth complex is active by itself, i.e., no co-catalyst is necessary to initiate the polymerization. However, this is limited to the case of neodymium, or bulky ansa-metallocenes. In general, the performances are improved when an alkylating reagent and/or an activator are associated to the allylic compound. Regarding conjugated dienes, allyl complexes afford catalysts that enable the production of polymers with high stereoselectivity, along with very high activities.

The complexes synthesized by most research teams often focus on the "small" REs, i.e., the late lanthanides-having small size ionic radius-also including yttrium and scandium, especially when they are of the CGC-type. In turn, when it comes to metallocene-like derivatives, "big" RE, i.e., the early lanthanides, also including lanthanum, are privileged. In general, many scandium complexes in a given series afford the best catalyst, particularly as far as pseudo-cationic processes are concerned, which corroborates a recent theoretical study by Hou and coworkers [42].

Most allyl complexes of the RE described in this review are cyclopentadienyl derivatives, at the exception of the mixed allyl-borohydrides series recently reported. Such mixed allyl-borohydrides undoubtedly foreshadow a new platform towards novel families of allyl rare earth post-metallocenes.

Although allyl complexes of the rare earths may sometimes be difficult to isolate, their synthesis is clearly worth the effort. Indeed, the hapticity of the allyl ligand can assist in isolating a compound where the alkyl analog is not stable, and also limits the coordination of an additional solvent molecule, which may be detrimental to the catalytic performances. Moreover, as illustrated in this mini-review, allyl complexes may be obtained under a monomeric form, which can favor the reactivity vs. bridged alkyl complexes. So far, the presence of an allyl ligand does not guarantee the reactivity towards the insertion reaction of a monomer molecule and, hence, the polymerization: this allyl moiety must be effectively reactive. The fluxionality of the allyl ligand, as seen by proton NMR, can be an indication of a possible reactivity: it is quite frequently observed that the most active catalyst in a series often corresponds to the complex whose allyl ligand has a certain degree of fluxionality. However, this does not seem to be generalizable for the larger rare earths.

Nevertheless, in most cases the help of a co-catalyst and/or an activator is mandatory, at least to improve the catalytic performances, or to better control the process, especially when the reactions are conducted under reversible chain transfer conditions.

It can be anticipated that further research will be conducted in this area of chemistry for the years to come. 
Table 1. Summary of complexes and their polymerizations.

\begin{tabular}{|c|c|c|c|c|c|c|c|c|}
\hline Complex $^{1}$ & Allyl Flux. $\left({ }^{1} \mathrm{H}\right.$ NMR) & Cocat. & Activ. $^{2}$ & Butadiene $^{1}$ Sel./TOF ${ }^{3}$ & Isoprene $^{1}$ Sel./.TOF $^{3}$ & Styrene $^{1}$ Sel.//TOF ${ }^{3}$ & Copolymers $^{1}$ Sel.//TOF ${ }^{3}$ & Reference \\
\hline \multirow{3}{*}{$\underline{\mathbf{1}_{\mathbf{Y}}}, \mathbf{1}_{\mathrm{La}}, \mathbf{1}_{\mathrm{Nd}}$} & \multirow{3}{*}{$\begin{array}{c}\text { yes }(\mathrm{Y}) \\
\text { no }(\mathrm{La}, \mathrm{Nd})\end{array}$} & - & - & inactive & & & & \multirow{3}{*}{ [13] } \\
\hline & & \multirow{2}{*}{$\mathrm{Al}^{i} \mathrm{Bu}_{3}$} & - & 1,4-cis $90 \% / 10,000 \mathrm{~h}^{-1}$ & & & & \\
\hline & & & HNB & $1,4-$ cis $92.5 \% / 12,000 \mathrm{~h}^{-1}$ & & & & \\
\hline \multirow{5}{*}{$1_{\mathrm{Sc}}$} & \multirow{5}{*}{ yes } & \multirow{2}{*}{$\mathrm{Al}^{i} \mathrm{Bu}_{3}$} & - & not selective $/ 280 \mathrm{~h}^{-1}$ & & & & \multirow{5}{*}{ [23] } \\
\hline & & & HNB & not selective $/ 1600 \mathrm{~h}^{-1}$ & & & & \\
\hline & & - & - & inactive & & inactive & & \\
\hline & & \multirow{2}{*}{$\mathrm{Al}^{i} \mathrm{Bu}_{3}$} & - & & & atactic/95 $\mathrm{h}^{-1}$ & & \\
\hline & & & HNB & & & atactic $/ 114 \mathrm{~h}^{-1}$ & & \\
\hline \multirow{2}{*}{$\underline{2 \underline{Y}}, 2_{\mathrm{La}}$} & \multirow{2}{*}{$\begin{array}{l}\text { yes }(\mathrm{Y}) \\
\text { no }(\mathrm{La})\end{array}$} & - & - & inactive & & & & \multirow{2}{*}{ [21] } \\
\hline & & $\mathrm{Al}^{i} \mathrm{Bu}_{3}$ & & $1,4-$ cis $86 \% / 12,000 \mathrm{~h}^{-1}$ & & & & \\
\hline $3_{\mathrm{Lu}}$ & yes & - & ТВ & 1,4-cis $97 \% / 60,000 \mathrm{~h}^{-1}$ & & Syndiotactic/60,000 $\mathrm{h}^{-1}$ & $c i s-\mathrm{PI}-b-\mathrm{sPS} / 5000 \mathrm{~h}^{-1}$ & [24] \\
\hline $3 \mathrm{Y}, \underline{3 \mathrm{sc}}$ & $\begin{array}{c}\text { no (Y) } \\
\text { yes (Sc) }\end{array}$ & - & ТВ & & & Syndiotactic/60,000 $\mathrm{h}^{-1}$ & & [35] \\
\hline $4_{\mathrm{Y}}, 4_{\mathrm{Nd}}, \underline{4_{\mathrm{Gd}}}, 4_{\mathrm{Dy}}$ & \multirow[t]{3}{*}{ yes $(\mathrm{Y})$} & $\mathrm{Al}^{i} \mathrm{Bu}_{3}$ & HNB & & $\begin{array}{c}\text { 1,4-cis } 99 \% / 1000 \mathrm{~h}^{-1} \\
\left(3000 \mathrm{~h}^{-1}, \mathrm{Nd}\right) \\
\text { CCG with excess } \\
\mathrm{Al}^{i} \mathrm{Bu}_{3}\end{array}$ & & $\begin{array}{c}c i s-\mathrm{PI}-b-c i s-\mathrm{PB} ; \\
\text { cis-PI-b-cis-PB-b-cis-PI }\end{array}$ & \multirow[t]{3}{*}{ [26] } \\
\hline \multirow{2}{*}{$4_{Y}, 4_{L u}$} & & - & HNB & & & inactive & & \\
\hline & & $\mathrm{Al}^{i} \mathrm{Bu}_{3}$ & HNB & & & inactive & & \\
\hline \multirow{2}{*}{$\underline{5_{Y}}, 5_{\mathrm{Ho}}, 5_{\mathrm{Lu}}$} & \multirow{4}{*}{ yes $(\mathrm{Y}, \mathrm{Lu})$} & - & - & & inactive & & & \multirow{4}{*}[27]{} \\
\hline & & - & $\mathrm{HNB} / \mathrm{TB}$ & & $\begin{array}{c}3,4-79 \% / 100 \mathrm{~h}^{-1} \\
\left(500 \mathrm{~h}^{-1}, \mathrm{Lu}\right)\end{array}$ & & & \\
\hline \multirow{2}{*}{$5_{Y}, \underline{5_{\mathrm{Ho}}}, 5_{\mathrm{Lu}}$} & & $\mathrm{AlMe}_{3}$ & HNB & & 1,4 -trans $72 \% / 2000 \mathrm{~h}^{-1}$ & & & \\
\hline & & $\mathrm{Al}^{i} \mathrm{Bu}_{3}$ & & & $1,4-c i s 74 \% / 1000 \mathrm{~h}^{-1}$ & & & \\
\hline \multirow{4}{*}{$6_{\mathrm{Nd}}$} & & - & - & & inactive & & & \multirow{4}{*}{ [27] } \\
\hline & & - & $\mathrm{HNB} / \mathrm{TB}$ & & $3,4-66 \% / 500 \mathrm{~h}^{-1}$ & & & \\
\hline & & $\mathrm{AlMe}_{3}$ & HNB & & 1,4 -trans $85 \% / 2000 \mathrm{~h}^{-1}$ & & & \\
\hline & & $\mathrm{Al}^{i} \mathrm{Bu}_{3}$ & & & $3,4-85 \% / 1000 \mathrm{~h}^{-1}$ & & & \\
\hline
\end{tabular}


Table 1. Cont.

\begin{tabular}{|c|c|c|c|c|c|c|c|}
\hline Complex $^{1}$ & Allyl Flux. ('H NMR) & Cocat. & Butadiene $^{1}$ Sel./TOF ${ }^{3}$ & Isoprene $^{1}$ Sel./TOF ${ }^{3}$ & Styrene $^{1}$ Sel./TOF ${ }^{3}$ & Copolymers $^{1}$ Sel.//TOF ${ }^{3}$ & Reference \\
\hline $7_{\mathrm{Y}}, 7_{\mathrm{Lu}}$ & no $(\mathrm{Y}, \mathrm{Lu})[23]$ & - & photo-activation & not selective (3,4 major) & & & [28] \\
\hline \multirow{3}{*}{$8_{\mathrm{Nd}}, 8_{\mathrm{Sm}}$} & \multirow{3}{*}{ no $(\mathrm{Nd}, \mathrm{Sm})$} & - & - & 1,4 -trans $92 \% / 180 \mathrm{~h}^{-1}$ & & & \multirow{3}{*}{ [29] } \\
\hline & & $\mathrm{Mg}^{n} \mathrm{Bu}_{2}$ & - & 1,4 -trans $95.5 \% / 425 \mathrm{~h}^{-1}$ & & & \\
\hline & & $\mathrm{Al}^{i} \mathrm{Bu}_{3}$ & - & 1,4 -cis $78 \% / 1000 \mathrm{~h}^{-1}$ & & & \\
\hline \multirow{3}{*}{$9_{Y}$} & & - & - & 1,4 -trans $91 \% / 70 \mathrm{~h}^{-1}$ & Isotactic $/ 14,400 \mathrm{~h}^{-1}$ [31] & $\begin{array}{l}\text { 1,4-trans-PI-co-iPS } \\
\text { 1,4-trans-PI- } b \text {-iPS }\end{array}$ & \multirow[b]{2}{*}{ [32] } \\
\hline & & $\mathrm{Mg}^{n} \mathrm{Bu}_{2}$ & - & $\begin{array}{l}\text { 1,4-trans } 90 \% / 76 \mathrm{~h}^{-1} \\
\text { CCTP with excess } \\
\mathrm{Mg}^{n} \mathrm{Bu}_{2}\end{array}$ & & & \\
\hline & & $\mathrm{Mg}^{n} \mathrm{Bu}_{2}$ & - & & $\begin{array}{l}\text { Isotactic/2100 } \mathrm{h}^{-1} \\
\text { CCTP with excess } \\
\mathrm{Mg}^{n} \mathrm{Bu}_{2}\end{array}$ & & [34] \\
\hline \multirow{2}{*}{$10_{S_{\mathrm{C}}}, 10_{\mathrm{Y}}, 10_{\mathrm{Lu}}$} & \multirow{2}{*}{ yes $(S c, Y, L u)$} & - & TB & & Syndiotactic $/ 250 \mathrm{~h}^{-1}$ & & [35] \\
\hline & & $\mathrm{Al}^{i} \mathrm{Bu}_{3}$ & $\mathrm{~TB}$ & & Syndiotactic/1500 $\mathrm{h}^{-1}$ & & \\
\hline \multirow[b]{2}{*}{$11_{\mathrm{Nd}}$} & & - & - & & Syndiotactic/ $60 \mathrm{~h}^{-1}$ & & \multirow[b]{2}{*}{ [34] } \\
\hline & & $\mathrm{Mg}^{n} \mathrm{Bu}_{2}$ & - & & $\begin{array}{c}\text { Syndiotactic } / 2500 \mathrm{~h}^{-1} \\
\text { CCTP with excess } \\
\mathrm{Mg}^{n} \mathrm{Bu}_{2}\end{array}$ & & \\
\hline
\end{tabular}

${ }^{1}$ The activity/selectivity refers to the best result obtained for a given metal within a given series, and corresponding to the underlined complex. ${ }^{2} \mathrm{HNB}=\left\{\left[\mathrm{HNMe}{ }_{2} \mathrm{Ph}\right]\left[\mathrm{B}\left(\mathrm{C}_{6} \mathrm{~F}_{5}\right)_{4}\right]\right\}$, $\mathrm{TB}=\left\{\left[\mathrm{CPh}_{3}\right]\left[\mathrm{B}\left(\mathrm{C}_{6} \mathrm{~F}_{5}\right)_{4}\right]\right\} .{ }^{3}$ In mol monomer $/ \mathrm{mol}$ catalyst $/ \mathrm{h}$. 
Acknowledgments: The Ministère de l'Enseignement Supérieur et de la Recherche (Ph.D. grant to S.F.) the Région Nord-Pas de Calais, and the FEDER are acknowledged for supporting and funding this work. Y. Champouret is greatly acknowledged for careful reading of this manuscript.

Author Contributions: The authors contributed equally to the writing of the paper.

Conflicts of Interest: The authors declare no conflict of interest. The founding sponsors had no role in the design of the study; in the collection, analyses, or interpretation of data; in the writing of the manuscript; or in the decision to publish the results.

\section{References and Notes}

1. Muthmann, W.; Kraft, K. Untersuchungen über das Cer und das Lanthan. Liebigs Ann. Chem. 1902, 325, 261-278. [CrossRef]

2. Porri, L.; Giarrusso, A. Conjugated diene polymerization. In Comprehensive Polymer Science; Eastmond, G., Ledwith, A., Russo, S., Sigwalt, P., Eds.; Pergamon: Oxford, UK, 1989; Volume 4, pp. 53-108. ISBN 978-0-08-096701-1.

3. Evans, W.J.; Ulibarri, T.A.; Ziller, J.W. Reactivity of $\left(\mathrm{C}_{5} \mathrm{Me}_{5}\right)_{2} \mathrm{Sm}$ and related species with alkenes: Synthesis and structural characterization of a series of organosamarium allyl complexes. J. Am. Chem. Soc. 1990, 112, 2314-2324. [CrossRef]

4. Taube, R.; Windisch, H.; Maiwald, S. The catalysis of the stereospecific butadiene polymerization by Allyl Nickel and Allyl Lanthanide complexes-A mechanistic comparison. Macromol. Symp. 1995, 89, 393-409. [CrossRef]

5. Kuran, W. Coordination Polymerisation of conjugated dienes. In Principles of Coordination Polymerisation; J. Wiley and Sons: Chichester, UK, 2001; Chapter 5, pp. 275-329.

6. Fischbach, A.; Anwander, R. Rare-Earth Metals and Aluminum Getting Close in Ziegler-Type Organometallics. Adv. Polym. Sci. 2006, 204, 155-281.

7. Tsutsui, M.; Ely, N. Unusual type of organolanthanide complex containing the allyl moiety. Allylbis(.eta.5-cyclopentadienyl)lanthanide. J. Am. Chem. Soc. 1975, 97, 3551-3553. [CrossRef]

8. Taube, R.; Sylvester, G. Applied Homogeneous Catalysis with Organometallic Compounds; Cornils, B., Herrmann, W.A., Eds.; VCH: Weinheim, Germany, 1996; Chapter 2.3, pp. 280-318.

9. Casely, I.J.; Suh, Y.S.; Ziller, J.W.; Evans, W.J. Formation of a [ONN(allyl)O]-Anion via NO Insertion and Coupling Using Yttrium and Lanthanide Allyl Metallocenes. Organometallics 2010, 29, 5209-5214. [CrossRef]

10. Fieser, M.E.; Mueller, T.J.; Bates, J.E.; Ziller, J.W.; Furche, F.; Evans, W.J. Differentiating Chemically Similar Lewis Acid Sites in Heterobimetallic Complexes: The Rare-Earth Bridged Hydride $\left(\mathrm{C}_{5} \mathrm{Me}_{5}\right)_{2} \mathrm{Ln}(\mu-\mathrm{H})_{2} \mathrm{Ln}{ }^{\prime}\left(\mathrm{C}_{5} \mathrm{Me}_{5}\right)_{2}$ and Tuckover Hydride $\left(\mathrm{C}_{5} \mathrm{Me}_{5}\right)_{2} \mathrm{Ln}(\mu-\mathrm{H})\left(\mu-\eta^{1}: \eta^{5}-\mathrm{CH}_{2} \mathrm{C}_{5} \mathrm{Me}_{4}\right) \operatorname{Ln}{ }^{\prime}\left(\mathrm{C}_{5} \mathrm{Me}_{5}\right)$ Systems. Organometallics 2014, 33, 3882-3890. [CrossRef]

11. Cui, P.; Spaniol, T.P.; Maron, L.; Okuda, J. Dehydrogenation of Amine-Borane $\mathrm{Me}_{2} \mathrm{NH} \cdot \mathrm{BH}_{3}$ Catalyzed by a Lanthanum-Hydride Complex. Chem. Eur. J. 2013, 19, 13437-13444. [CrossRef] [PubMed]

12. Abinet, E.; Spaniol, T.P.; Okuda, J. Olefin Hydrosilylation Catalysts Based on Allyl Bis(phenolato) Complexes of the Early Lanthanides. Chem. Asian J. 2011, 6, 389-391. [CrossRef] [PubMed]

13. Evans, W.J.; Kozimor, S.A.; Brady, J.C.; Davis, B.L.; Nyce, G.W.; Seibel, C.A.; Ziller, J.W.; Doedens, R.J. Metallocene Allyl Reactivity in the Presence of Alkenes Tethered to Cyclopentadienyl Ligands. Organometallics 2005, 24, 2269-2278. [CrossRef]

14. Taube, R.; Windisch, H.; Maiwald, S.; Hemling, H.; Schumann, H. XLVIII 1. Synthese und Struktur der ersten neutralen Tris(allyl)lanthanoid-Komplexe $\mathrm{La}\left(\eta^{3}-\mathrm{C}_{3} \mathrm{H}_{5}\right)_{3} .1,5$ Dioxan und $\mathrm{Nd}\left(\eta^{3}-\mathrm{C}_{3} \mathrm{H}_{5}\right)_{3}$. Dioxan und ihre Eignung als "single site"-Katalysatoren fur die stereospezifische Butadienpolymerisation. J. Orgamomet. Chem. 1996, 513, 49-61. [CrossRef]

15. Barbier-Baudry, D.; Bonnet, F.; Dormond, A.; Hafid, A.; Nyassi, A.; Visseaux, M. Organolanthanides, catalysts for specific olefin-diene copolymerization: Access to new materials. J. Alloys Compd. 2001, 323, 592-596. [CrossRef]

16. Kirillov, E.; Lehmann, C.W.; Razavi, A.; Carpentier, J.-F. Highly Syndiospecific Polymerization of Styrene Catalyzed by Allyl Lanthanide Complexes. J. Am. Chem. Soc. 2004, 126, 12240-12241. [CrossRef] [PubMed] 
17. Kang, X.; Zhou, G.; Wang, X.; Qu, J.; Hou, Z.; Luo, Y. Alkyl Effects on the Chain Initiation Efficiency of Olefin Polymerization by Cationic Half-Sandwich Scandium Catalysts: A DFT Study. Organometallics 2016, 35, 913-920. [CrossRef]

18. Carpentier, J.-F.; Guillaume, S.; Kirillov, E.; Sarazin, Y. Discrete allyl complexes of group 3 metals and lanthanides. Comptes Rendus Chim. 2010, 13, 608-625. [CrossRef]

19. Brydson, J.A. Aliphatic Polyolefins other than Polyethylene, and Diene Rubbers. In Plastics Materials, 7th ed.; Butterworth-Heinemann: Oxford, UK; Elsevier: Armstrong, The Netherlands, 1999; Chapter 11, pp. 247-310. ISBN 978-0-7506-4132-6.

20. Taube, R.; Windisch, H.; Görlitz, F.H.; Schumann, H. Komplexkatalyse: XL. Darstellung und Kristallstruktur des Tetra(allyl) lanthanat(III)-Komplexes $\left[\mathrm{Li}\left(\mu-\mathrm{C}_{4} \mathrm{H}_{8} \mathrm{O}_{2}\right)_{3 / 2}\right]\left[\mathrm{La}\left(\eta^{3}-\mathrm{C}_{3} \mathrm{H}_{5}\right)_{4}\right]$, eines Katalysators fur die stereospezifische Butadienpolymerisation. J. Organomet. Chem. 1993, 445, 85-91. [CrossRef]

21. Robert, D.; Abinet, E.; Spaniol, T.P.; Okuda, J. Cationic Allyl Complexes of the Rare-Earth Metals: Synthesis, Structural Characterization, and 1,3-Butadiene Polymerization Catalysis. Chem. Eur. J. 2009, 15, 11937-11947. [CrossRef] [PubMed]

22. The lanthanum and the neodymium $\left.\operatorname{Ln}(\operatorname{allyl})_{2}\right]\left[\mathrm{B}\left(\mathrm{C}_{6} \mathrm{~F}_{5}\right)_{4}\right]$ ionic pairs were described and assessed as single-component catalysts for butadiene polymerization but experimental details are lacking, see: Taube, R. Catalytic Reaction Mechanisms and Structure-Reactivity Relationships in the Stereospecific Butadiene Polymerization. In Metalorganic Catalysts for Synthesis and Polymerization; Kaminsky, W., Ed.; Springer: Berlin, Germany, 1999; pp. 531-546, ISBN 978-3-642-60178-1.

23. Standfuss, S.; Abinet, E.; Spaniol, T.P.; Okuda, J. Allyl complexes of scandium: Synthesis and structure of neutral, cationic and anionic derivatives. Chem. Commun. 2011, 47, 11441-11443. [CrossRef] [PubMed]

24. Jian, Z.; Tang, S.; Cui, D. A Lutetium Allyl Complex That Bears a Pyridyl-Functionalized Cyclopentadienyl Ligand: Dual Catalysis on Highly Syndiospecific and cis-1,4-Selective (Co)Polymerizations of Styrene and Butadiene. Chem. Eur. J. 2010, 16, 14007-14015. [CrossRef] [PubMed]

25. Senyek, M.L. Isoprene, polymers. In Encyclopedia of Polymer Science and Technology; Wiley: Hoboken, NJ, USA, 2002.

26. Jian, Z.; Cui, D.; Hou, Z.; Li, X. Living catalyzed-chain-growth polymerization and block copolymerization of isoprene by rare-earth metal allyl precursors bearing a constrained-geometry-conformation ligand. Chem. Commun. 2010, 46, 3022-3024. [CrossRef] [PubMed]

27. Jende, L.N.; Hollfelder, C.O.; Maichle-Mössmer, C.; Anwander, R. Rare-Earth-Metal Allyl Complexes Supported by the [2-(N,N-Dimethylamino)ethyl]tetramethylcyclopentadienyl Ligand: Structural Characterization, Reactivity, and Isoprene Polymerization. Organometallics 2015, 34, 32-41. [CrossRef]

28. Fieser, M.E.; Johnson, C.W.; Bates, J.E.; Ziller, J.W.; Furche, F.; Evans, W.J. Dinitrogen Reduction, Sulfur Reduction, and Isoprene Polymerization via Photochemical Activation of Trivalent Bis(cyclopentadienyl) Rare-Earth-Metal Allyl Complexes. Organometallics 2015, 34, 4387-4393. [CrossRef]

29. Fadlallah, S.; Terrier, M.; Jones, C.; Roussel, P.; Bonnet, F.; Visseaux, M. Mixed Allyl-Borohydride Lanthanide Complexes: Synthesis of $\mathrm{Ln}\left(\mathrm{BH}_{4}\right)_{2}\left(\mathrm{C}_{3} \mathrm{H}_{5}\right)(\mathrm{THF})_{3}(\mathrm{Ln}=\mathrm{Nd}, \mathrm{Sm})$, Characterization, and Reactivity towards Polymerization. Organometallics 2016, 35, 456-461. [CrossRef]

30. Fadlallah, S.; Jothieswaran, J.; Capet, F.; Bonnet, F.; Visseaux, M. Mixed Allyl Rare-Earth Borohydride Complexes: Synthesis, Structure, and Application in (Co-)Polymerization Catalysis of Cyclic Esters. Chem. Eur. J. 2017, 23, 15644-15654. [CrossRef] [PubMed]

31. Rodrigues, A.; Kirillov, E.; Roisnel, T.; Razavi, A.; Vuillemin, B.; Carpentier, J.F. Highly Isospecific Styrene Polymerization Catalyzed by Single-Component Bridged Bis(indenyl) Allyl Yttrium and Neodymium Complexes. Angew. Chem. Int. Ed. 2007, 46, 7240-7243. [CrossRef] [PubMed]

32. Annunziata, L.; Duc, M.; Carpentier, J.F. Chain Growth Polymerization of Isoprene and Stereoselective IsopreneStyrene Copolymerization Promoted by an ansa-Bis(indenyl)allylYttrium Complex. Macromolecules 2011, 44, 7158-7166. [CrossRef]

33. Luo, Y.; Chi, S.; Chen, J. Half-sandwich rare-earth-metal derivatives bearing pyrrolidinyl-functionalized cyclopentadienyl ligand: Synthesis, characterization and catalysis in syndiospecific polymerization of styrene. New J. Chem. 2013, 37, 2675-2682. [CrossRef]

34. Sarazin, Y.; de Frémont, P.; Annunziata, L.; Duc, M.; Carpentier, J.F. Syndio- and Isoselective Coordinative Chain Transfer Polymerization of Styrene Promoted by ansa-Lanthanidocene/ Dialkylmagnesium Systems. Adv. Synth. Catal. 2011, 353, 1367-1374. [CrossRef] 
35. Jian, Z.; Cui, D.; Hou, Z. Rare-Earth-Metal-Hydrocarbyl Complexes Bearing Linked Cyclopentadienyl or Fluorenyl Ligands: Synthesis, Catalyzed Styrene Polymerization, and Structure-Reactivity Relationship. Chem. Eur. J. 2012, 18, 2674-2684. [CrossRef] [PubMed]

36. Shannon, R.D. Revised Effective Ionic Radii and Systematic Studies of Interatomie Distances in Halides and Chaleogenides. Acta Cryst. 1976, 32, 751-767. [CrossRef]

37. This represents an activity comparable to the most active titanium and scandium catalysts, see Coates, G.W. Precise Control of Polyolefin Stereochemistry Using Single-Site Metal Catalysts. Chem. Rev. 2000, 100, 1223-1252.

38. Bonnet, F.; Violante, C.; Roussel, P.; Mortreux, A.; Visseaux, M. Unprecedented dual behaviour of a half-sandwich scandium-based initiator for both highly selective isoprene and styrene polymerisation. Chem. Commun. 2009, 23, 3380-3382. [CrossRef] [PubMed]

39. Annunziata, L.; Rodrigues, A.S.; Kirillov, E.; Sarazin, Y.; Okuda, J.; Perrin, L.; Maron, L.; Carpentier, J.F. Isoselective Styrene Polymerization Catalyzed by ansa-Bis(indenyl) Allyl Rare Earth Complexes. Stereochemical and Mechanistic Aspects. Macromolecules 2011, 44, 3312-3322. [CrossRef]

40. Rodrigues, A.-S.; Kirillov, E.; Lehmann, C.W.; Roisnel, T.; Vuillemin, B.; Razavi, A.; Carpentier, J.-F. Allyl ansa-Lanthanidocenes: Single-Component, Single-Site Catalysts for Controlled Syndiospecific Styrene and Styrene-Ethylene (Co)Polymerization. Chem. Eur. J. 2007, 13, 5548-5565. [CrossRef] [PubMed]

41. Perrin, L.; Kirillov, E.; Carpentier, J.F.; Maron, L. DFT Investigation of the Tacticity Control during Styrene Polymerization Catalyzed by Single-Component Allyl ansa-Lanthanidocenes $\left\{\left(\mathrm{C}_{5} \mathrm{H}_{4} \mathrm{CMe}_{2}\left(9-\mathrm{C}_{13} \mathrm{H}_{8}\right)\right\} \mathrm{Ln}\left(\mathrm{C}_{3} \mathrm{H}_{5}\right)\right.$. Macromolecules 2010, 43, 6330-6336. [CrossRef]

42. Kang, X.; Song, Y.; Luo, Y.; Li, G.; Hou, Z.; Qu, J. Computational Studies on Isospecific Polymerization of 1-Hexene Catalyzed by Cationic Rare Earth Metal Alkyl Complex Bearing a C3 iPr-trisox Ligand. Macromolecules 2012, 45, 640-651. [CrossRef]

(C) 2017 by the authors. Licensee MDPI, Basel, Switzerland. This article is an open access article distributed under the terms and conditions of the Creative Commons Attribution (CC BY) license (http:/ / creativecommons.org/licenses/by/4.0/). 